\title{
High efavirenz levels but not neurofilament light plasma levels are associated with poor neurocognitive functioning in asymptomatic HIV patients
}

\author{
Charlotte S. Hakkers ${ }^{1}$ (D) Anne Marie Hermans ${ }^{1} \cdot$ Erik M. van Maarseveen $^{2} \cdot$ Charlotte E. Teunissen $^{3}$. \\ Inge M. W. Verberk ${ }^{3}$ • Joop E. Arends ${ }^{1}$ • Andy I. M. Hoepelman ${ }^{1}$
}

Received: 27 August 2019 / Revised: 10 May 2020 / Accepted: 19 May 2020 / Published online: 10 June 2020

(C) The Author(s) 2020

\begin{abstract}
The aim of this study is to assess the effect of efavirenz exposure on neurocognitive functioning and investigate plasma neurofilament light $(\mathrm{Nfl})$ as a biomarker for neurocognitive damage. Sub-analysis of the ESCAPE-study, a randomised controlled trial where virologically suppressed, cognitively asymptomatic HIV patients were randomised (2:1) to switch to rilpivirine or continue on efavirenz. At baseline and week 12, patients underwent an extensive neuropsychological assessment (NPA), and serum efavirenz concentration and plasma Nfl levels were measured. Subgroups of elevated $(\geq 4.0 \mathrm{mg} / \mathrm{L})$ and therapeutic $(0.74$ to $<4.0 \mathrm{mg} / \mathrm{L}$ ) baseline efavirenz concentration were made. Differences between these groups in baseline NPA Z-scores and in delta scores after efavirenz discontinuation were assessed. Nfl level was measured using an ELISA analysis using single molecule array (Simoa) technology. Correlation of plasma NFL with NPA Z-scores was evaluated using a linear mixed model. The elevated group consisted of 6 patients and the therapeutic group of 48 . At baseline, the elevated group showed lower composite Z-scores (median - 1.03; IQR 0.87 versus $0.27 ; 0.79 . p 0.02)$. This effect was also seen on the subdomains verbal $(p 0.01)$, executive functioning $(p 0.02)$, attention $(p<0.01)$ and speed $(p 0.01)$. In the switch group, the elevated group improved more on composite scores after discontinuing efavirenz (mean 0.58 ; SD 0.32 versus $0.22 ; 0.54, p 0.15$ ). No association between plasma $\mathrm{Nfl}$ and composite Z-score was found. High efavirenz exposure is associated with worse cognitive functioning compared with patients with therapeutic concentrations. Plasma Nfl is not a suitable biomarker to measure cognitive damage in this group.
\end{abstract}

Keywords HIV $\cdot$ Efavirenz $\cdot$ Cognition $\cdot$ Asymptomatic $\cdot$ Neurofilament light

\section{Introduction}

Antiretroviral agents used to treat infection with human immunodeficiency virus 1 (HIV) have been associated with

Electronic supplementary material The online version of this article (https://doi.org/10.1007/s13365-020-00860-1) contains supplementary material, which is available to authorized users.

Charlotte S. Hakkers

c.s.hakkers@umcutrecht.nl

1 Department of Internal Medicine, section Infectious Diseases, University Medical Center (UMC) Utrecht, Utrecht University, PO Box 85500, 3508, GA Utrecht, the Netherlands

2 Division of Laboratory and Pharmacy, Clinical Pharmacy, University Medical Center (UMC) Utrecht, Utrecht, the Netherlands

3 Department of Clinical Chemistry, Amsterdam Neuroscience Neurochemistry laboratory, Vrije Universiteit Amsterdam, Amsterdam UMC, Amsterdam, the Netherlands neurocognitive Impairment (NCI) (Robertson et al. 2010; Shah et al. 2016). Especially efavirenz, a non-nucleoside reverse transcriptase inhibitor, is known for its neurological and psychiatric side effects and has been associated with higher rates of NCI (Muñoz-Moreno et al. 2009; Arendt et al. 2007; Ciccarelli et al. 2011; Decloedt and Maartens 2013; Abers et al. 2014; Gaida et al. 2016). Even in patients without clinically manifested cognitive complaints (cognitively asymptomatic patients), a negative effect of efavirenz on cognition has been shown (Robertson et al. 2010). In the ESCAPE study, we found that discontinuing efavirenz led to an objective improvement in neurocognitive functioning in a group of asymptomatic people with HIV (Hakkers et al. 2019). However, efavirenz remains a popular choice in antiretroviral therapy, mainly in resource-limited settings, mainly because is it part of Atripla, a single-tablet regime that is relatively cheap and has a convenient once a day dosage.

Multiple mechanisms on how efavirenz causes neurotoxicity have been described through in vitro and in vivo studies. For instance, a neurotoxic effect of efavirenz and its major metabolite 
8-hydroxy-efavirenz was found in neuronal cultures, affecting dendrites and dendritic processes (Robertson et al. 2012; Tovar-y-Romo et al. 2012; Ciavatta et al. 2017). Moreover, studies have shown a detrimental effect of efavirenz on the bloodbrain barrier and on neuronal action potential thresholds (Bertrand and Toborek 2015; Ciavatta et al. 2017). Effects on other mechanisms such as calcium homoeostasis or creatine kinase metabolism have also been shown (Streck et al. 2008; Tovar-y-Romo et al. 2012). Most studies show a concentrationdependent effect of efavirenz on CNS side effects such as impaired concentration, and this is most notable from serum concentrations above $>4 \mathrm{mg} / \mathrm{L}$ (Marzolini et al. 2001; Borand et al. 2014). It might therefore be interesting to investigate the effect of high serum efavirenz concentrations on cognition.

Furthermore, there is a need for fast and patient-friendly diagnostic tools (biomarkers) for diagnosing neurocognitive damage, because the current gold standard, a neuropsychological assessment (NPA), is timely and expensive. Recent interest has emerged in a protein called neurofilament light (Nfl) which is a major structural component of axons and is released into the cerebrospinal fluid (CSF) and blood upon axonal damage and neuronal death (Varhaug et al. 2018). CSF Nfl is elevated in patients suffering from HIV-associated dementia (Yilmaz et al. 2017). The recent development of an ultrasensitive immunoassay for plasma Nfl using single molecule array (Simoa) technology allows testing for neurocognitive injury in plasma instead of CSF (Kuhle et al. 2016). Several studies have established that there is a strong correlation between plasma Nfl and CSF Nfl (Rojas et al. 2016; Meeter et al. 2016; Wilke et al. 2016; Piehl et al. 2017; Kovacs et al. 2017). Besides HIV infection, plasma $\mathrm{Nfl}$ has been investigated in neurological conditions such as frontotemporal dementia, multiple sclerosis and Creutzfeldt disease and proven to be useful as a biomarker of neurodegeneration (Rohrer et al. 2016; Steinacker et al. 2016; Kuhle et al. 2017). The results from two studies suggest that plasma Nfl may provide an almost equally good indicator of active CNS injury compared with CSF Nfl in people with HIV (Gisslén et al. 2016; Anderson et al. 2018).

Given the demonstrated improvement in neurocognitive functioning in earlier studies after discontinuing efavirenz, the main hypothesis of this study is that this observed effect is related to efavirenz exposure, measured by elevated serum drug levels. Furthermore, we investigate the hypothesis that a high exposure to efavirenz leads to axonal damage and/or neuronal cell death, which can be measured by plasma $\mathrm{Nfl}$.

\section{Methods}

\section{Participants}

This study is a sub-analysis of the ESCAPE trial (Effect of SwitChing AtriPla to Eviplera on neurocognitive and emotional functioning) which was previously published (Hakkers et al. 2019). In short, this randomised controlled trial included neurologically asymptomatic, stable (i.e. undetectable viral load), HIV-infected male patients on efavirenz/ emtricitabine/tenofovir (Atripla) for at least 6 months, aged from 25 to 50 years old. Participants were excluded if they had active or past CNS opportunistic infections, active psychiatric of neurologic disorders and/or a history or evidence of alcohol or drug abuse. The study was performed according to the declaration of Helsinki and was reviewed and approved by the medical ethical board of the University Medical Center Utrecht. All participants signed written informed consent (Hakkers et al. 2019).

\section{Study design}

In the ESCAPE study, participants were randomised to the switch group, where they would switch to rilpivirine/ emtricitabine/tenofovir (Eviplera), or the control group (continuing on Atripla) with a randomisation ratio of 2:1. At baseline and study week 12 , blood was collected for serum measurement of efavirenz concentration and plasma measurement of NFL concentrations, as well as HIV-RNA and CD4 cell count. Also, a comprehensive NPA was performed. Seven cognitive domains were tested by the NPA: language, learning and memory, executive functioning, attention/working memory, speed of information processing and psychomotor speed (Hakkers et al. 2019). The different subtests used were as follows: Controlled Oral Word Association Test (Schmand et al. 2008); category fluency(Van der Elst et al. 2006); Rey Auditory Verbal Learning Test; Rey complex figure test (A Rey 1941); trail making test part A and B (Reitan and Wolfson 1985); Brixton Spatial Anticipation Test (Burgess and Shallice 1997); visual elevator (Robertson et al. 1994); Paced Auditory Serial Addition Test (Gronwall and Samspon 1974); Letter-Number-Sequencing WAIS-IV NL, Digit Symbol WAIS-IV NL and Symbol Search WAIS-IV NL (Wechsler 2013); and Grooved Pegboard (dominant and non-dominant)(Roy and Square-Storer 1994). When possible, different test versions were used on baseline and for week 12, in order to minimise repeated testing effects. By using Dutch norm data, domain Z-scores were calculated, and a composite Z-score was calculated taking all different domains into account. A Z-score correlates to the amount of standard deviations a person deviates from the mean of the norm group, so a higher Z-score means a better performance.

\section{Efavirenz concentration analysis}

For the analysis of efavirenz serum concentrations, an aliquot of $50 \mu \mathrm{L}$ serum was diluted with $200 \mu \mathrm{L} 0.1 \mathrm{M}$ zinc sulphate and $500 \mu \mathrm{L}$ internal standard solution. The vials were vortexed for $1 \mathrm{~min}$ and centrifuged at 13,000 rpm for $5 \mathrm{~min}$, 
and $25 \mu \mathrm{L}$ was injected on the LC-MS/MS system, a Thermo Fisher Scientific (Waltham, MA, USA) triple quadrupole Quantum Access LC-MS/MS system with a Surveyor MS pump and a Surveyor Plus autosampler with an integrated column oven. The Quantum Access mass selective detector was set in electrospray positive ionisation mode and performed selected reaction monitoring. Data acquisition and data processing were performed using Xcalibur software version 2.10. The analytical column was a HyPurity C18 $50 \mathrm{~mm} \times$ $2.1 \mathrm{~mm}$ column with $3 \mu \mathrm{m}$ particle size (Thermo Scientific). Analytes were detected by a Thermo Fisher Scientific (Waltham, MA) triple quadrupole Quantum Access detector using heated electrospray ionisation (HESI). Ions monitored in the selected reaction monitoring (SRM) mode regression coefficient $\left(R^{2}\right)$ were 0.98 . The lower limit of quantification (LLQ) was $0.1 \mathrm{mg} / \mathrm{L}$. Accuracy and precision were within the maximum tolerated bias and coefficient of variation, $20 \%$ for LLQ and $15 \%$ for medium and high quality controls.

\section{Plasma NFL analysis}

Plasma NfL concentrations were quantified in blood by the Neurochemistry Laboratory, Amsterdam UMC, location VUmc, using an in-house developed Homebrew Simoa assay, validated according to the standardised international protocols and described in detail elsewhere (Limberg et al. 2015; Kuhle et al. 2016). The monoclonal NfL capture antibody (Anti NfL mAb 47:3; UmanDiagnostics, Umeå, Sweden) was titrated to $0.3 \mathrm{mg} / \mathrm{mL}$ and chemically coupled to paramagnetic carboxylated beads (Quanterix, Lexington, USA). The assay had a lower limit of quantification of $1.54 \mathrm{pg} / \mathrm{mL}$. All samples were measured in duplicate.

\section{Statistical analysis}

Initially, all participants were divided into two groups: elevated baseline concentration of efavirenz, meaning a concentration of $\geq 4.0 \mathrm{mg} / \mathrm{L}$, and therapeutic baseline concentration of efavirenz, meaning a concentration of $<4.0 \mathrm{mg} / \mathrm{L}$. This division was made at baseline in the entire population to assess concentration effects on NPA Z-score in a cross-sectional manner and again at baseline in only the switch group to investigate longitudinal effects.

Subsequently, differences in baseline characteristics (age, education, employment status, BMI, duration of HIV infection and cART, current and nadir CD4) between elevated and therapeutic concentration groups were investigated. For categorical variables, either a chi-squared test or Fisher's exact test (if values were expected to be below five) was used, and for continuous variables, either an independent sample $t$ test for normal distribution or a Mann-Whitney $U$ test for skewed distribution was used. Level of education according to the Verhage scale (Verhage 1964) was divided in high (group six and seven) and low (< group six). Differences between NPA Z-scores of the two groups at baseline were analysed using an independent samples $t$ test for normal distribution or a Mann-Whitney $U$ test for skewed distribution. With the same approach, difference ('delta') scores of NPA Z-scores were assessed in the switch group.

Then, to evaluate the effect of plasma NFL on composite Z-score, a linear mixed model with random intercept was built combining measurements at baseline and end of study, resulting in 108 measurements. The variable concentration of efavirenz was transformed to a log variable to ensure better fitting of the model. A restricted maximum likelihood linear mixed model was run to investigate the effect of plasma NfL on composite Z-score, including the following covariates (i.e. fixed effects): age, neuropsychiatric comedication, months on cART, CD4 count, HIV disease duration, CD4 nadir, concentration of efavirenz and 'time point in study' (marked as a categorical variable). Duration of efavirenz use in terms of months was left out of the analysis because of the by now reached steady state of this drug. Participants were defined as random effects to correct for multiple measurements in one participant. After building a full mixed model, the backward method according to the principle of a linear regression was used to investigate factors of interest (i.e. plasma $\mathrm{NfL}$ and other fixed effects) by building a final model. This model was again fit by restricted maximum likelihood.

Finally, to investigate disturbing influences on plasma NfL alone, a univariable and multivariable linear regression was performed. Factors with a $p$ value $<0.20$ in the univariable models, or with a scientific rationale, were entered in the multivariable linear regression model. The backward method was used, and $p<0.05$ was applied as a cut-off level for acceptance. Only five variables were entered, approximately one per every ten participants.

Mixed model analyses were performed using R Statistical Software version 3.3.2; for the remaining analyses, IBM SPSS version 21 was used. Overall, an alpha of $<0.05$ was used as a cut-off.

\section{Results}

In the ESCAPE trial, a total of 54 participants were included. Participants were divided into therapeutic baseline efavirenz concentration $(n=48)$ and elevated baseline efavirenz concentration $(n=6)$ (Fig. 1). There was no significant difference between patient characteristics of these groups at baseline, except for employment status $(p=0.03)$ (Table 1$)$.

\section{Effect of efavirenz concentration on NPA}

Participants with an elevated concentration of efavirenz at baseline had a significantly lower NPA composite Z-score 
Fig. 1 Flowchart. EFV, efavirenz

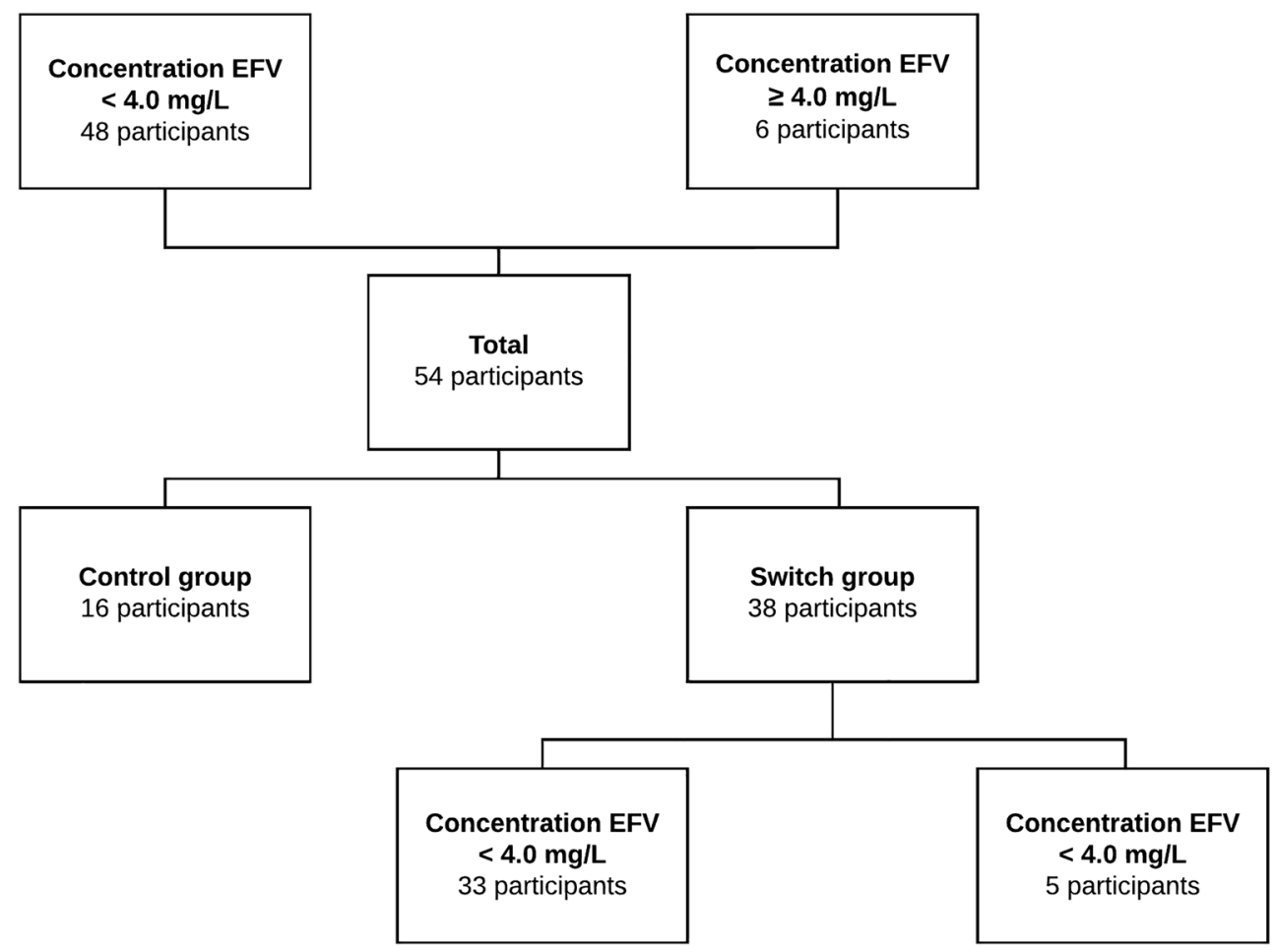

Abbreviations: $\mathrm{EFV}=$ efavirenz

(i.e. decreased cognitive function) at baseline compared with those with a therapeutic efavirenz concentration $(-1.03$; IQR
0.87 versus 0.27 ; IQR $0.79, p=0.02$ ). When analysing the specific domains, elevated efavirenz concentrations were

Table 1 Baseline characteristics

\begin{tabular}{|c|c|c|c|c|}
\hline Variable & $\begin{array}{l}\text { Total } \\
N=54(100 \%)\end{array}$ & $\begin{array}{l}\text { Concentration } \\
\mathrm{EFV}<4.0 \mathrm{ng} / \mathrm{mL} \\
N=48(88.9 \%)\end{array}$ & $\begin{array}{l}\text { Concentration } \\
\mathrm{EFV} \geq 4.0 \mathrm{ng} / \mathrm{mL} \\
N=6(11.1 \%)\end{array}$ & $p$ value \\
\hline Age, in years & $41(11)$ & $41(11)$ & $43(11)$ & 0.81 \\
\hline $\begin{array}{l}\text { High educational attainment according } \\
\text { to Verhage (group } 6 \text { and } 7 \text { ), } N(\%)\end{array}$ & $26(48.1)$ & $23(47.9)$ & $3(50.0)$ & 0.63 \\
\hline $\begin{array}{l}\text { Employed } \\
N(\%)\end{array}$ & $51(94.4)$ & $47(97.9)$ & $4(66.7)$ & 0.03 \\
\hline BMI, in $\mathrm{kg} / \mathrm{m}^{2}$ mean $\pm \mathrm{SD}$ & $24.1 \pm 3.3$ & $24.1 \pm 3.5$ & $23.4 \pm 2.7$ & 0.52 \\
\hline Use of neuropsychiatric medication, $N(\%)$ & $7(13.0)$ & $6(12.5)$ & $1(16.7)$ & 0.58 \\
\hline cART, in months & $58(51)$ & $58(50)$ & $58(85)$ & 0.99 \\
\hline $\mathrm{EFV}$ treatment duration, in months mean $\pm \mathrm{SD}$ & $56 \pm 28$ & $56 \pm 29$ & $56 \pm 24$ & 0.88 \\
\hline $\mathrm{CD} 4$ count, in cell $/ \mathrm{mm} 3$ & $605(268)$ & $620(255)$ & $546(365)$ & 0.46 \\
\hline CD4 nadir, in cell $/ \mathrm{mm}^{3}$ & $295(138)$ & $275(144)$ & $355(100)$ & 0.05 \\
\hline HIV disease duration, in months & $92(56)$ & $92(51)$ & $85(140)$ & 0.85 \\
\hline EFV concentration, in $\mathrm{mg} / \mathrm{L}$ & $2.16(1.50)$ & $1.80(1.31)$ & $7.11(9.67)$ & $<0.01$ \\
\hline Plasma NFL, in pg/mL & $21.6(16.6)$ & $21.6(16.8)$ & $20.7(24.3)$ & 0.82 \\
\hline
\end{tabular}

Values shown as median (IQR), unless otherwise specified

$*$ Difference considered significant ( $p$ value $<0.05$ )

$N$ number, $E F V$ efavirenz, IQR interquartile range, $B M I$ body mass index, $S D$ standard deviation, $c A R T$ combination antiretroviral therapy, $H I V$ human immunodeficiency virus, $N F L$ neurofilament light 
associated with lower NPA scores in the following domains: verbal ( -0.66 ; SD 0.83 versus 0.41 ; SD $0.93, p=0.01)$, executive functioning $(-0.59$; SD 0.78 versus 0.26 ; SD 0.83 , $p=0.02)$, attention $(-2.05$; SD 1.33 versus -0.35 ; SD 1.04 , $p<0.01)$ and speed $(-1.08$; SD 0.81 versus 0.07 ; SD 1.00, $p=0.01$ ) (Table 2).

Next, we evaluated only the group of participants that switched from a regimen with efavirenz to a regimen without efavirenz in order to study the effect of efavirenz discontinuation. Differences ('delta-scores') between NPA Z-scores on baseline and end of study were investigated. In the switch group, 5 participants had an elevated concentration, and 33 participants had a therapeutic concentration of efavirenz (Fig. 1). All participants improved on the second NPA due to a learning effect. Participants with an elevated concentration at baseline had a higher delta, i.e. improved more on composite Z-score (0.58; SD 0.32 versus 0.22 ; SD $0.54, p=0.15$ ) compared with those with a therapeutic concentration. When looking at subdomains, the group with an elevated baseline concentration of efavirenz improved more on the domains verbal ( $0.47 \mathrm{SD} 0.42$ versus $0.15 \mathrm{SD} 0.64, p=0.63$ ), attention ( 0.98 SD 0.67 versus 0.46 SD $0.6 p=0.33)$, speed $(0.93$; SD 0.73 ; versus 0.42 ; SD $0.41, p=0.05$ ), motor $(0.80 \mathrm{SD} 0.36$ versus $0.54 \mathrm{SD} 0.85, p=0.18)$ and learning $(0.80 \mathrm{SD} 0.31$ versus $0.41 \mathrm{SD} 1.00 p=0.65$ ) (Fig. 2; Table 3). Although none of these improvements were statistically significant, a trend towards significance was seen in the domain speed.

Because of the significant difference between the two groups in employment status and the near-significant difference in nadir CD4, we ran an extra GLM including these factors, and they had no effect on both outcomes (Z-score or delta Z-score).

\section{NFL as a biomarker for neurocognitive impairment}

To evaluate whether Nfl plasma concentration is related to neurocognitive impairment, a linear mixed model with random intercept was built. The full model contained 8 covariates (age, use of psychoactive comedication, duration of cART and HIV infection, current and nadir CD4, efavirenz concentration and time point in study (baseline or week 12)). A significant relation was found between composite Z-score and time point in the study indicating that all patients increased their Z-score on the second time point, which can be explained by a learning effect from doing the NPA for the second time. (coefficient $=0.26$, standard error $=0.0746, p=$ $<0.01)$. No other factors had a significant association with composite Z-score (Table 4). A final model was created by using the backward method, containing four variables (use of psychoactive comedication, duration of cART, efavirenz concentration, time point in study). Plasma NFL still did not show a significant association with the outcome composite Z-score (coefficient $=0.0012$, standard error $=0.0030, p=0.71$ ).

Next, we investigated which variables had an effect on plasma $\mathrm{Nfl}$ in order to identify possible disturbing influences in Nfl levels. Univariable linear regression on plasma neurofilament light at baseline showed no significant association, except for HIV disease duration ( $p=0.32 ; p=0.02$ ) (supplemental data). For the multivariable linear regression, 5 variables were entered in the model, age $(p=0.12)$, months on cART ( $p=0.08)$, CD4 nadir ( $p=0.96$ ), HIV disease duration $(\mathrm{p}=0.02)$ and viral load at baseline $(p=0.14)$ (supplemental data). When creating a multivariable linear regression model using the backward method, only HIV disease duration remained statistically significant (coefficient 0.090 , standard error $=0.037, p=0.02$ ).

\section{Discussion}

This is the first study that aimed to investigate the effect of efavirenz exposure, measured by plasma concentration, on objectively measured cognitive functioning in cognitively asymptomatic people with HIV. An elevated efavirenz
Table 2 NPA Z-scores at baseline in normal and high concentration of EFV groups

\begin{tabular}{lllr}
\hline $\begin{array}{l}\text { Type of NPA } \\
\text { Z-score }\end{array}$ & $\begin{array}{l}\text { Concentration } \\
\text { EFV }<4.0 \mathrm{mg} / \mathrm{L}\end{array}$ & $\begin{array}{l}\text { Concentration } \\
\mathrm{EFV} \geq 4.0 \mathrm{mg} / \mathrm{L}\end{array}$ & $p$ value \\
\hline Composite & $0.27(0.79)$ & $-1.03(0.87)$ & 0.02 \\
median (IQR) & $0.41 \pm 0.93$ & $-0.66 \pm 0.83$ & 0.01 \\
Domain verbal & $-0.04 \pm 0.50$ & $-0.18 \pm 0.46$ & 0.52 \\
Domain memory & $0.26 \pm 0.83$ & $-0.59 \pm 0.78$ & 0.02 \\
Domain executive functioning & $-0.35 \pm 1.04$ & $-2.05 \pm 1.33$ & $<0.01$ \\
Domain attention & $0.07 \pm 1.00$ & $-1.08 \pm 0.81$ & 0.01 \\
Domain speed & $0.18(1.24)$ & $-1.14(2.98)$ & 0.08 \\
Domain motor & $0.33 \pm 0.68$ & $0.12 \pm 1.02$ & 0.52 \\
median (IQR) & & & \\
Domain learning & & & \\
\hline
\end{tabular}


Fig. 2 Mean composite Z-scores with confidence intervals in the switch group, divided at baseline in therapeutic and elevated concentration of efavirenz

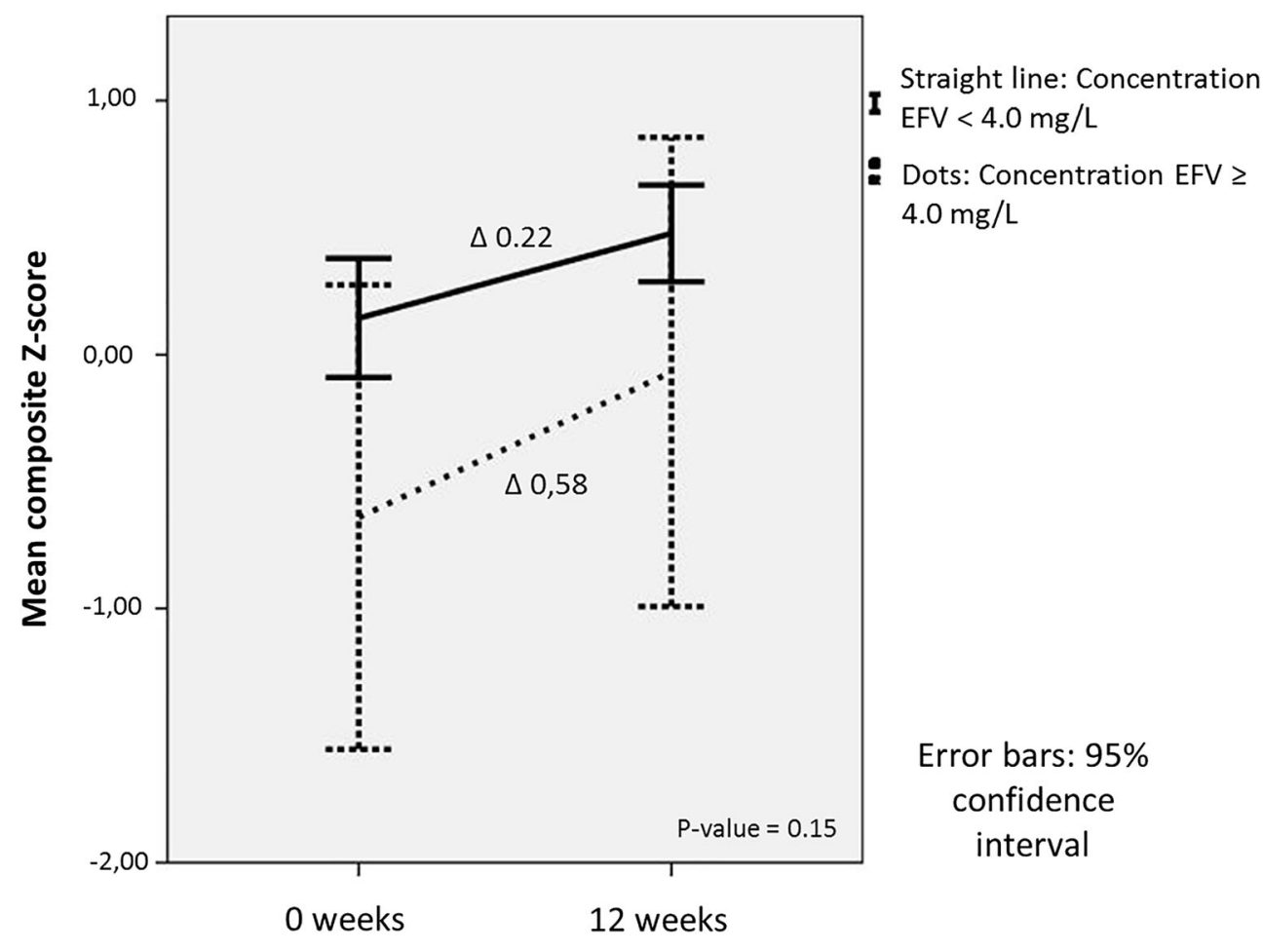

concentration was associated with worse cognitive functioning overall and in different domains (verbal, executive functioning, attention and speed). Furthermore, discontinuing efavirenz resulted in more neurocognitive improvement in those with an elevated efavirenz baseline concentration compared with those with a therapeutic efavirenz baseline concentration. However, this effect was not statistically significant, apart from a trend in the subdomain speed, most likely due to a limited sample size. Moreover, when exploring the use of plasma $\mathrm{Nfl}$ as a biomarker in neurocognitive functioning, no association between plasma $\mathrm{Nfl}$ and composite Z-score was found.
Patients usually switch to another (efavirenz-sparing) regimen when they experience neurocognitive side effects. However, there is a group of patients that tolerate efavirenz and do not experience a clinically significant effect on cognition. The strength of our study lies in the fact that we analysed the effect of efavirenz concentration in these cognitively asymptomatic people with HIV, as opposed to patients with overt neurocognitive complaints. The domains that showed the largest effect of elevated efavirenz concentration (speed and attention) are also the cognitive domains that were mostly affected by discontinuing efavirenz in the ESCAPE trial.
Table 3 Difference ('delta') scores of NPA Z-scores in normal and high concentration of EFV groups within the switch group

\begin{tabular}{llll}
\hline $\begin{array}{l}\text { Type of NPA } \\
\text { Z-score }\end{array}$ & $\begin{array}{l}\text { Concentration } \\
\text { EFV }<4.0 \mathrm{mg} / \mathrm{L}\end{array}$ & $\begin{array}{l}\text { Concentration } \\
\text { EFV } \geq 4.0 \mathrm{mg} / \mathrm{L}\end{array}$ & $p$ value \\
\hline Composite & $0.22(0.54)$ & $0.58(0.32)$ & 0.15 \\
median (IQR) & $0.15 \pm 0.64$ & $0.47 \pm 0.42$ & 0.63 \\
Domain verbal & $-0.24 \pm 0.49$ & $-0.03 \pm 0.73$ & 0.48 \\
Domain memory & $0.42 \pm 0.52$ & $0.33 \pm 0.30$ & 0.82 \\
Domain executive functioning & $0.46 \pm 0.60$ & $0.98 \pm 0.67$ & 0.33 \\
Domain attention & $0.42 \pm 0.41$ & $0.93 \pm 0.73$ & 0.05 \\
Domain speed & $0.54 \pm 0.85$ & $0.80 \pm 0.36$ & 0.18 \\
Domain motor & $0.41 \pm 1.00$ & $0.80 \pm 0.31$ & 0.65 \\
Domain learning & & & \\
\hline
\end{tabular}

Values shown as mean $\pm \mathrm{SD}$, unless otherwise specified

*Difference between groups considered significant ( $p$ value $<0.05$ )

$N P A$ neuropsychological assessment, $E F V$ efavirenz, $I Q R$ interquartile range, $S D$ standard deviation 
Table 4 Full linear mixed model on the outcome composite Zscore

\begin{tabular}{lccc}
\hline Fixed effect & Coefficient & Standard error & $p$ value \\
\hline Intercept & 0.38381 & 0.66321 & 0.57 \\
Age, in years & -0.00065 & 0.01631 & 0.97 \\
Use of neuropsychiatric medication & 0.15100 & 0.33070 & 0.65 \\
cART, in months & -0.00378 & 0.00441 & 0.40 \\
CD4 count, in cell $/ \mathrm{mm}^{3}$ & -0.00008 & 0.00030 & 0.78 \\
CD4 nadir, in cell $/ \mathrm{mm}^{3}$ & -0.00010 & 0.00072 & 0.89 \\
HIV disease duration, in months & 0.00006 & 0.00345 & 0.99 \\
EFV concentration, in mg/L* & -0.07816 & 0.05470 & 0.17 \\
Plasma NFL, in pg/mL & 0.00117 & 0.00355 & 0.75 \\
Time point in study** & 0.26045 & 0.07457 & $<0.01$ \\
\hline Efavirenz concentration transformed to log variable & & \\
$* *$ Time is defined as a categorical variable & & \\
cART combination antiretroviral therapy, $H I V$ human immunodeficiency virus, NFL neurofilament light
\end{tabular}

Although toxicity thresholds from 2.74 to $4.7 \mathrm{mg} / \mathrm{L}$ for efavirenz have been used in studies (Núñez et al. 2001; Gutierrez et al. 2005), we chose to use a cut-off level of $4.0 \mathrm{mg} / \mathrm{L}$ for efavirenz concentration, seeing as this is the most used threshold in the international literature (Marzolini et al. 2001; Gallego et al. 2004; Kappelhoff et al. 2005; Burger et al. 2006; Naidoo et al. 2014). In order to measure cognition in a fast and less time-consuming manner, there is a need for biomarkers that can preferably be measured in plasma. Plasma $\mathrm{Nfl}$ has been shown to be useful in providing an indication of active CNS injury in HIV infection (Gisslén et al. 2016; Anderson et al. 2018). However, these studies found the most significant results in patients with HIV dementia or in untreated people with HIV. The current study is the first study that aimed to explore the utility of plasma $\mathrm{Nfl}$ as a biomarker in treated cognitively asymptomatic patients with HIV. An association between plasma Nfl and composite Z-score was not found. Moreover, the concentration of efavirenz did not have a significant association in this relationship, and therefore, the switch in regime was not a contributing factor in explaining the association between plasma $\mathrm{Nfl}$ and composite Z-score in this analysis. The hypothesis of this study that efavirenz causes axonal damage, and therefore results in rising plasma Nfl levels, could therefore not be proven in this study. The negative effects of efavirenz on the brain might be explained by other mechanisms than axonal damage. In vitro studies did show a larger effect of efavirenz on dendrite cells than axonal cells (Robertson et al. 2012; Tovar-y-Romo et al. 2012; Ciavatta et al. 2017). Furthermore, most studies found that neuronal death, which would also be measured by Nfl, was not the major reason for neurotoxicity of efavirenz (Robertson et al. 2012). Another explanation could be that plasma Nfl is not as sensitive as CSF Nfl, as is suggested in animal studies (Bacioglu et al. 2016).

There are some limitations to this study. First, the small number of participants was due to the limited number included in the time-consuming ESCAPE trial. Since no power calculation was done for this sub-analysis, it is possible that the used numbers do not provide sufficient power for the analysis. Moreover, there was a substantial difference between the amount of patients in the two groups (6 versus 48 ) that further reduced our power. Second, in contrast to previous reports on Nfl (Gisslén et al. 2016), in this study, plasma Nfl did not correlate with age. This could be explained by the fact that the variation in age was limited in this population due to the study inclusion criteria. Moreover, studies have shown that the correlation between age and Nfl levels is more evident in healthy controls (Khalil et al. 2013). However, this study found a significant correlation with duration of HIV infection and plasma Nfl levels. This effect might be explained by the hypothesis that HIV infection itself together with the accompanying chronic immune activation has an added neurotoxic effect. Furthermore, people who have been infected with HIV for a longer period have consequently been on more and older cART regimens. Previous cART regimens possibly did cause axonal damage and therefore caused higher levels of plasma NFL (Schmued et al. 1996; Fodale et al. 2005; Pettersen et al. 2006; Xu et al. 2014). Considering the fact that detecting $\mathrm{Nfl}$ in plasma is a recent development, an all-encompassing answer explaining all possible factors influencing plasma/serum NfL levels is not yet available. Therefore, it is important to further investigate the applicability and validity of plasma $\mathrm{Nfl}$ as a biomarker, preferably in larger cohorts of people with HIV suffering from neurocognitive impairment.

In conclusion, elevated serum efavirenz concentration is associated with worse cognitive functioning, and there are signs that subsequent discontinuation results in improvement of cognitive functioning compared with those with normal concentrations. Plasma Nfl is not suitable as a biomarker for cognitive damage in this group. 
Authors' contributions CSH: study design, data collection, statistical analysis, writing manuscript. AMH: statistical analysis, writing manuscript. EMvM: study design, data collection, statistical analysis. CT: data collection, writing manuscript. IMWV: data collection, writing manuscript. JEA: study design, statistical analysis, writing manuscript. AIMH: study design, writing manuscript.

\section{Compliance with ethical standards}

The study was performed according to the declaration of Helsinki and was reviewed and approved by the medical ethical board of the University Medical Center Utrecht. All participants signed written informed consent

Conflict of interest The authors declare that they have no conflict of interest.

Open Access This article is licensed under a Creative Commons Attribution 4.0 International License, which permits use, sharing, adaptation, distribution and reproduction in any medium or format, as long as you give appropriate credit to the original author(s) and the source, provide a link to the Creative Commons licence, and indicate if changes were made. The images or other third party material in this article are included in the article's Creative Commons licence, unless indicated otherwise in a credit line to the material. If material is not included in the article's Creative Commons licence and your intended use is not permitted by statutory regulation or exceeds the permitted use, you will need to obtain permission directly from the copyright holder. To view a copy of this licence, visit http://creativecommons.org/licenses/by/4.0/.

\section{References}

Abers MS, Shandera WX, Kass JS (2014) Neurological and psychiatric adverse effects of antiretroviral drugs. CNS Drugs 28:131-145. https://doi.org/10.1007/s40263-013-0132-4

Anderson AM, Easley KA, Kasher N, Franklin D, Heaton RK, Zetterberg H, Blennow K, Gisslen M, Letendre SL (2018) Neurofilament light chain in blood is negatively associated with neuropsychological performance in HIV-infected adults and declines with initiation of antiretroviral therapy. J Neuro-Oncol 24:695-701. https://doi.org/10. 1007/s13365-018-0664-y

Arendt G, de Nocker D, von Giesen H-J, Nolting T (2007) Neuropsychiatric side effects of efavirenz therapy. Expert Opin Drug Saf 6:147-154. https://doi.org/10.1517/14740338.6.2.147

Bacioglu M, Maia LF, Preische O, Schelle J, Apel A, Kaeser SA, Schweighauser M, Eninger T, Lambert M, Pilotto A, Shimshek DR, Neumann U, Kahle PJ, Staufenbiel M, Neumann M, Maetzler W, Kuhle J, Jucker M (2016) Neurofilament light chain in blood and CSF as marker of disease progression in mouse models and in neurodegenerative diseases. Neuron 91:494-496. https://doi.org/10. 1016/j.neuron.2016.07.007

Bertrand L, Toborek M (2015) Dysregulation of endoplasmic reticulum stress and autophagic responses by the antiretroviral drug efavirenz. Mol Pharmacol 88:304-315. https://doi.org/10.1124/mol.115. 098590

Borand L, Madec Y, Laureillard D, Chou M, Marcy O, Pheng P, Prak N, Kim C, Lak KK, Hak C, Dim B, Nerrienet E, Fontanet A, Sok T, Goldfeld AE, Blanc FX, Taburet AM (2014) Plasma concentrations, efficacy and safety of efavirenz in HIV-infected adults treated for tuberculosis in Cambodia (ANRS 1295-CIPRA KH001 CAMELIA trial). PLoS One 9:e90350. https://doi.org/10.1371/journal.pone. 0090350
Burger D, van der Heiden I, la Porte C, van der Ende M, Groeneveld P, Richter C, Koopmans P, Kroon F, Sprenger H, Lindemans J, Schenk $\mathrm{P}$, van Schaik R (2006) Interpatient variability in the pharmacokinetics of the HIV non-nucleoside reverse transcriptase inhibitor efavirenz: the effect of gender, race, and CYP2B6 polymorphism. Br J Clin Pharmacol 61:148-154. https://doi.org/10.1111/j.13652125.2005.02536.x

Burgess PW, Shallice T (1997) The hayling and Brixton tests

Ciavatta VT, Bichler EK, Speigel IA, Elder CC, Teng SL, Tyor WR, García PS (2017) In vitro and ex vivo neurotoxic effects of efavirenz are greater than those of other common antiretrovirals. Neurochem Res 42:3220-3232. https://doi.org/10.1007/s11064-017-2358-x

Ciccarelli N, Fabbiani M, Di Giambenedetto S et al (2011) Efavirenz associated with cognitive disorders in otherwise asymptomatic HIV-infected patients. Neurology 76:1403-1409. https://doi.org/ 10.1212/WNL.0b013e31821670fb

Decloedt EH, Maartens G (2013) Neuronal toxicity of efavirenz: a systematic review. Expert Opin Drug Saf 12:841-846. https://doi.org/ 10.1517/14740338.2013.823396

Fodale V, Mazzeo A, Praticò C, Aguennouz M, Toscano A, Santamaria LB, Vita G (2005) Fatal exacerbation of peripheral neuropathy during lamivudine therapy: evidence for iatrogenic mitochondrial damage. Anaesthesia 60:806-810. https://doi.org/10.1111/j.1365-2044. 2005.04208.x

Gaida R, Truter I, Grobler C, Kotze T, Godman B (2016) A review of trials investigating efavirenz-induced neuropsychiatric side effects and the implications. Expert Rev Anti-Infect Ther 14:377-388. https://doi.org/10.1586/14787210.2016.1157469

Gallego L, Barreiro P, del Río R et al (2004) Analyzing sleep abnormalities in HIV-infected patients treated with efavirenz. Clin Infect Dis 38:430-432. https://doi.org/10.1086/380791

Gisslén M, Price RW, Andreasson U, Norgren N, Nilsson S, Hagberg L, Fuchs D, Spudich S, Blennow K, Zetterberg H (2016) Plasma concentration of the neurofilament light protein (NFL) is a biomarker of CNS injury in HIV infection: a cross-sectional study. EBioMedicine 3:135-140. https://doi.org/10.1016/j.ebiom.2015.11.036

Gronwall D, Samspon H (1974) The psychological effects of concussion Gutierrez F, Navarro A, Padilla S, Anton R, Masia M, Borras J, MartinHidalgo A (2005) Prediction of neuropsychiatric adverse events associated with long-term efavirenz therapy, using plasma drug level monitoring. Clin Infect Dis 41:1648-1653. https://doi.org/10. $1086 / 497835$

Hakkers CS, Arends JE, van den Berk GE, Ensing MHM, Hooijenga I, Vink M, van Zandvoort MJE, Hoepelman AIM (2019) Objective and subjective improvement of cognition after discontinuing efavirenz in asymptomatic patients. JAIDS J Acquir Immune Defic Syndr 80:e14-e22. https://doi.org/10.1097/QAI. 0000000000001876

Kappelhoff BS, van Leth F, Robinson PA, MacGregor T, Baraldi E, Montella F, Uip DE, Thompson MA, Russell DB, Lange JM, Beijnen JH, Huitema AD, 2NN Study Group (2005) Are adverse events of nevirapine and efavirenz related to plasma concentrations? Antivir Ther 10:489-498

Khalil M, Enzinger C, Langkammer C, Ropele S, Mader A, Trentini A, Vane MLG, Wallner-Blazek M, Bachmaier G, Archelos JJ, KoelSimmelink MJA, Blankenstein MA, Fuchs S, Fazekas F, Teunissen CE (2013) CSF neurofilament and N-acetylaspartate related brain changes in clinically isolated syndrome. Mult Scler 19:436-442. https://doi.org/10.1177/1352458512458010

Kovacs GG, Andreasson U, Liman V, Regelsberger G, Lutz MI, Danics K, Keller E, Zetterberg H, Blennow K (2017) Plasma and cerebrospinal fluid tau and neurofilament concentrations in rapidly progressive neurological syndromes: a neuropathology-based cohort. Eur J Neurol 24:1326-1e77. https://doi.org/10.1111/ene.13389

Kuhle J, Barro C, Andreasson U, Derfuss T, Lindberg R, Sandelius Å, Liman V, Norgren N, Blennow K, Zetterberg H (2016) Comparison 
of three analytical platforms for quantification of the neurofilament light chain in blood samples: ELISA, electrochemiluminescence immunoassay and Simoa. Clin Chem Lab Med 54:1655-1661. https://doi.org/10.1515/cclm-2015-1195

Kuhle J, Nourbakhsh B, Grant D, Morant S, Barro C, Yaldizli Ö, Pelletier D, Giovannoni G, Waubant E, Gnanapavan S (2017) Serum neurofilament is associated with progression of brain atrophy and disability in early MS. Neurology 88:826-831. https://doi.org/10.1212/ WNL.0000000000003653

Limberg M, Disanto G, Barro C, Kuhle J (2015) Neurofilament light chain determination from peripheral blood samples. Humana Press, New York, NY, pp 93-98

Marzolini C, Telenti A, Decosterd LA, Greub G, Biollaz J, Buclin T (2001) Efavirenz plasma levels can predict treatment failure and central nervous system side effects in HIV-1-infected patients. AIDS 15:71-75

Meeter LH, Dopper EG, Jiskoot LC, Sanchez-Valle R, Graff C, Benussi L, Ghidoni R, Pijnenburg YA, Borroni B, Galimberti D, Laforce RJ, Masellis M, Vandenberghe R, Ber IL, Otto M, van Minkelen R, Papma JM, Rombouts SA, Balasa M, Öijerstedt L, Jelic V, Dick KM, Cash DM, Harding SR, Jorge Cardoso M, Ourselin S, Rossor MN, Padovani A, Scarpini E, Fenoglio C, Tartaglia MC, Lamari F, Barro C, Kuhle J, Rohrer JD, Teunissen CE, van Swieten JC (2016) Neurofilament light chain: a biomarker for genetic frontotemporal dementia. Ann Clin Transl Neurol 3:623-636. https://doi.org/10. $1002 / \operatorname{acn} 3.325$

Muñoz-Moreno JA, Fumaz CR, Ferrer MJ et al (2009) Neuropsychiatric symptoms associated with efavirenz: prevalence, correlates, and management. A neurobehavioral review. AIDS Rev 11:103-109

Naidoo P, Chetty VV, Chetty M (2014) Impact of CYP polymorphisms, ethnicity and sex differences in metabolism on dosing strategies: the case of efavirenz. Eur J Clin Pharmacol 70:379-389. https://doi.org/ 10.1007/s00228-013-1634-1

Núñez M, González de Requena D, Gallego L et al (2001) Higher efavirenz plasma levels correlate with development of insomnia. J Acquir Immune Defic Syndr 28:399-400

Pettersen JA, Jones G, Worthington C, Krentz HB, Keppler OT, Hoke A, Gill MJ, Power C (2006) Sensory neuropathy in human immunodeficiency virus/acquired immunodeficiency syndrome patients: protease inhibitor-mediated neurotoxicity. Ann Neurol 59:816-824. https://doi.org/10.1002/ana.20816

Piehl F, Kockum I, Khademi M, Blennow K, Lycke J, Zetterberg H, Olsson T (2017) Plasma neurofilament light chain levels in patients with MS switching from injectable therapies to fingolimod. Mult Scler J 135245851771513:1046-1054. https://doi.org/10.1177/ 1352458517715132

Reitan RM, Wolfson D (1985) The Halstead-Reitan Neuropsychological Test Battery: therapy and clinical interpretation

Rey A (1941) The Rey Auditory Verbal Learning Test. L'examen psychologique dans les cas d'encéphalopathie traumatique. Arch Psychol (Geneve) 28:286-340

Robertson IH, Ward T, Ridgeway V, Nimmo-Smith I (1994) The test of everyday attention

Robertson KR, Su Z, Margolis DM, Krambrink A, Havlir DV, Evans S, Skiest DJ, For the A5170 Study Team (2010) Neurocognitive effects of treatment interruption in stable HIV-positive patients in an observational cohort. Neurology 74:1260-1266

Robertson K, Liner J, Meeker RB (2012) Antiretroviral neurotoxicity. JNeurovirol 18:388-399. https://doi.org/10.1007/s13365-012-0120-3

Rohrer JD, Woollacott IOC, Dick KM, Brotherhood E, Gordon E, Fellows A, Toombs J, Druyeh R, Cardoso MJ, Ourselin S, Nicholas JM, Norgren N, Mead S, Andreasson U, Blennow K, Schott JM, Fox NC, Warren JD, Zetterberg H (2016) Serum neurofilament light chain protein is a measure of disease intensity in frontotemporal dementia. Neurology 87:1329-1336. https://doi. org/10.1212/WNL.0000000000003154
Rojas JC, Karydas A, Bang J, Tsai RM, Blennow K, Liman V, Kramer JH, Rosen H, Miller BL, Zetterberg H, Boxer AL (2016) Plasma neurofilament light chain predicts progression in progressive supranuclear palsy. Ann Clin Transl Neurol 3:216-225. https://doi. org/10.1002/acn3.290

Roy EA, Square-Storer PA (1994) Neuropsychology of movement sequencing disorders and apraxia

Schmand B, Groenink SC, van den Dungen M (2008) Letterfluency: psychometrische eigenschappen en Nederlandse normen. Tijdschr Gerontol Geriatr 39:64-76

Schmued LC, Albertson CM, Andrews A, Sandberg JA, Nickols J, Slikker W Jr (1996) Evaluation of brain and nerve pathology in rats chronically dosed with ddI or isoniazid. Neurotoxicol Teratol 18: 555-563. https://doi.org/10.1016/0892-0362(96)00088-8

Shah A, Gangwani MR, Chaudhari NS, Glazyrin A, Bhat HK, Kumar A (2016) Neurotoxicity in the post-HAART era: caution for the antiretroviral therapeutics. Neurotox Res 30:677-697. https://doi.org/ 10.1007/s12640-016-9646-0

Steinacker P, Blennow K, Halbgebauer S, Shi S, Ruf V, Oeckl P, Giese A, Kuhle J, Slivarichova D, Zetterberg H, Otto M (2016) Neurofilaments in blood and CSF for diagnosis and prediction of onset in Creutzfeldt-Jakob disease. Sci Rep 6:38737. https://doi.org/ 10.1038/srep38737

Streck EL, Scaini G, Rezin GT, Moreira J, Fochesato CM, Romão PRT (2008) Effects of the HIV treatment drugs nevirapine and efavirenz on brain creatine kinase activity. Metab Brain Dis 23:485-492. https://doi.org/10.1007/s11011-008-9109-2

Tovar-y-Romo LB, Bumpus NN, Pomerantz D, Avery LB, Sacktor N, McArthur JC, Haughey NJ (2012) Dendritic spine injury induced by the 8-hydroxy metabolite of efavirenz. J Pharmacol Exp Ther 343: 696-703. https://doi.org/10.1124/jpet.112.195701

Van der Elst W, Van Boxtel MPJ, Van Breukelen GJP, Jolles J (2006) Normative data for the animal, profession and letter M naming verbal fluency tests for Dutch speaking participants and the effects of age, education, and sex. J Int Neuropsychol Soc 12:80-89. https:// doi.org/10.1017/S1355617706060115

Varhaug KN, Barro C, Bjørnevik K, Myhr KM, Torkildsen $\varnothing$, Wergeland S, Bindoff LA, Kuhle J, Vedeler C (2018) Neurofilament light chain predicts disease activity in relapsingremitting MS. Neurol Neuroimmunol Neuroinflammation 5:e422. https://doi.org/10.1212/NXI.0000000000000422

Verhage F (1964) Intelligentie en leeftijd: Onderzoek bij Nederlanders van twaalf tot zevenenzeventig jaar. University of Groningen

Wechsler D (2013) Wechsler adult intelligence scale - fourth edition Nederlandstalige bewerking

Wilke C, Preische O, Deuschle C, Roeben B, Apel A, Barro C, Maia L, Maetzler W, Kuhle J, Synofzik M (2016) Neurofilament light chain in FTD is elevated not only in cerebrospinal fluid, but also in serum. J Neurol Neurosurg Psychiatry 87:1270-1272. https://doi.org/10. 1136/jnnp-2015-312972

Xu H, Wang Z, Zheng L, Zhang W, Lv H, Jin S, Yuan Y (2014) Lamivudine/telbivudine-associated neuromyopathy: neurogenic damage, mitochondrial dysfunction and mitochondrial DNA depletion. J Clin Pathol 67:999-1005. https://doi.org/10.1136/ JCLINPATH-2013-202069

Yilmaz A, Blennow K, Hagberg L, Nilsson S, Price RW, Schouten J, Spudich S, Underwood J, Zetterberg H, Gisslén M (2017) Neurofilament light chain protein as a marker of neuronal injury: review of its use in HIV-1 infection and reference values for HIVnegative controls. Expert Rev Mol Diagn 17:761-770. https://doi. org/10.1080/14737159.2017.1341313

Publisher's note Springer Nature remains neutral with regard to jurisdictional claims in published maps and institutional affiliations. 